\title{
Identificación molecular de Cynoscion analis y especies del género Merluccius por qPCR para la autentificación de productos hidrobiológicos congelados y conservas.
}

Molecular identification of Cynoscion and Merluccius species by qPCR for authentication of canned and frozen fish products.

\author{
Marcela Mora ${ }^{1}$, Liseth Huamancha ${ }^{1}$, Carlos Shiva ${ }^{1}$, Armando Hung ${ }^{1}$
}

\section{RESUMEN}

El objetivo del presente trabajo fue validar una reacción en cadena de la polimerasa (PCR) en tiempo real para detectar fragmentos pequeños de ADN con presencia de inhibidores e identificar genéticamente las especies pelágicas utilizadas comúnmente en conservas, harina de pescado y productos congelados. Se diseñaron cebadores para la detección de Cynoscion analis "ayanque" y especies del género Merluccius "merluza" utilizando regiones parciales del gen ATPase6 y regiones control con una longitud menor a $140 \mathrm{bp}$. Se detectó con alta especificidad y sensibilidad (100\%) ADN degradado a $121{ }^{\circ} \mathrm{C}$ por 30 minutos con un límite de detección: 0,00122 ng $\mu$ l-1 ADN Merluccius gayi gayi, 0,00116 ng $\mu$ l-1 ADN Merluccius gayi peruanus y 0,00163 ng $\mu$ l-1 ADN Cynoscion analis y eficiencias de amplificación por encima del $97 \%$. La validación del ensayo demuestra que el método es adecuado para la detección de ADN de ayanque y merluza en condiciones de degradación y con presencia de inhibidores. Se encontró la presencia de $\mathrm{ADN}$ de ayanque y merluza en conservas donde no están descritas estas especies en la etiqueta, el ensayo podría ser aplicado para la autentificación o detección de adulteración en productos hidrobiológicos congelados o sometidos a altas temperaturas durante su procesamiento.

PALABRAS CLAVE: Ayanque, merluza, qPCR, productos hidrobiológicos, adulteración.

\section{SUMMARY}

The objective was to validate a real time polymerase chain reaction (PCR) to detect DNA fragments in presence of inhibitors and identify pelagic species genetically in canned, fishmeal and frozen products. Primers were designed for the detection of Cynoscion analis "peruvian weakfish" and species of the genus Merluccius "hake" using partial regions of the ATPase6 gene and control regions with a length less than $140 \mathrm{bp}$. It was detected with high specificity and sensitivity $(100 \%)$ degraded DNA at $121{ }^{\circ} \mathrm{C}$ for 30 minutes, with a limit of detection of $0.00122 \mathrm{ng} \mu \mathrm{l}-1$ DNA Merluccius gayi gayi, $0.00116 \mathrm{ng} \mu \mathrm{l}-1$ DNA Merluccius gayi peruanus and $0.00163 \mathrm{ng}$ $\mu \mathrm{l}-1$ DNA Cynoscion analis and amplification efficiencies above $97 \%$. The validation of the test demonstrates that is suitable for the detection of peruvian weakfish and hake DNA under degradation conditions and with the presence of inhibitors. It was found the presence of peruvian weakfish and hake DNA in canned where these species are not 
described on the label. The assay could be applied for the authentication or detection of adulteration in frozen or high temperature hydrobiological products during its processing.

KEYWORDS: Peruvian weakfish, hake, qPCR, hydrobiological products, adulteration.

\section{INTRODUCCIÓN}

Según la Organización de las Naciones Unidas para la Alimentación y la Agricultura (FAO) en el 2016 el consumo mundial de pescado per cápita supera por primera vez los 20 kilogramos anuales. El pescado proporcionó el $6,7 \%$ de todas las proteínas consumidas por los seres humanos. Los países en desarrollo exportaron pescado por valor de 80000 millones de dólares, lo que supuso ingresos comerciales netos más elevados que los de la carne, tabaco, arroz y azúcar en conjunto. Esto ha llevado a una sobreexplotación de las especies de peces con valores comerciales como el ayanque, merluza, atún, bonito o jurel. Se considera que su captura es de una intensidad biológicamente insostenible y alarmante, además son difíciles de identificar y realizar la trazabilidad una vez procesado (FAO, 2016).

Según la normativa peruana, la anchoveta (Engraulis ringens) es el principal y único insumo que debe ser usado en la harina de pescado, regulando la prohibición de procesar los recursos hidrobiológicos como sardina, jurel y caballa (Ministerio de la Producción, 2007). Las empresas harineras y pescadores no cumplen la regulación y utilizan diversas especies de peces, entre ellas ayanque y merluza. El pescado y sus derivados juegan un rol importante en la nutrición del ser humano, pero también pueden ser un potente alimento alérgeno (Aas y Elsayed, 1969; De Martino et al., 1990; Bernhisel-Broadbent, Strause y Sampson, 1992; Kuehn, Scheuermann, Hilger y Hentges, 2010) por lo que productos alterados o etiquetas genéricas poco específicas en descripción del producto son un gran problema económico y de salud pública. Los productos hidrobiológicos varían en sus caracteristicas organolépticas lo que origina diferencias en las preferencias del consumidor y los valores comerciales. Ambas cuestiones requieren estrategias para garantizar la autenticidad del producto, y evitar la adulteración y una descripción incorrecta (Hargin, 1996).

Existen varias técnicas para la detección de las especies utilizadas en productos procesados como la microscopia clásica con un límite de detección menor al $0.1 \%$, espectroscopia del infrarrojo acoplado al microscopio (NIRM) que permite detectar componentes de origen animal, sin embargo, presenta dificultades para llegar a detectar la especie animal de la muestra analizada. La prueba de ELISA y tiras reactivas determina la presencia de proteínas específicas, pero presentan casos de falsos negativos debido a la pérdida de sensibilidad de proteínas que pasaron previamente por un proceso térmico (Bachur, 2014).

La prueba de reacción en cadena de la polimerasa (PCR) permite la detección de genes específicos y mejoró su eficiencia cuando se empleó PCR-RFLP, diversos métodos moleculares se han trabajado para la detección de especies de peces (Akasaki, Yanagimoto, Yamakami, Tomonaga, y Sato, 2006; Dooley, Sage, Clarke, Brown, y Garrett, 2005; Fumière, Dubois, Baeten, von Holst y Berben, 2009; Nagase, Maeta, Aimi, Suginaka, y Morinaga, 2009; Quinteiro et al. 2001; Wolf, Burgener, Hübner, y Lüthy, 2000). Sin embargo, esta técnica es más trabajosa, toma mayor tiempo y es menos específica y sensible que el qPCR. Muchas de las variantes de PCR para la identificación de ayanque y merluza trabajan con un producto de PCR de fragmentos largos, ineficiente para la detección de alimentos procesados en cocción y pasteurizados como conservas y harina de pescado, lo que dificulta la detección de ADN degradado reportando falsos negativos. Por lo tanto el estudio tiene por objetivo validar un PCR en tiempo real para detectar ADN altamente degradado de las especies Cynoscion analis "ayanque" y especies del género Merluccius "ayanque" y pueda ser empleado para la verificación de la autenticidad de los productos hidrobiológicos elaborados con Cynoscion analis "ayanque" y especies del género Merluccius "ayanque" encontradas en el Perú.

\section{MATERIAL Y MÉTODOS}

\section{Toma de muestra y extracción de ADN}

Se tomó muestras de las especies Merluccius gayi gayi, Merluccius gayi peruanus y Cynoscion analis, 10 peces por cada especie. Los ejemplares fueron 
identificados morfológicamente. El muestreo se realizó en agosto de 2016 en los terminales pesqueros de Lima en los distritos de Ventanilla y Villa María del Triunfo, y en el norte de Perú en las ciudades de Huacho, Chimbote y Chiclayo. Las muestras se trasladaron al laboratorio de Biología Molecular de la Facultad de Medicina Veterinaria y Zootecnia (FAVEZ) - Universidad Peruana Cayetano Heredia (UPCH), conservando la cadena de frío a $4{ }^{\circ} \mathrm{C}$.

La extracción de ADN para la elaboración de controles positivos y estandarización de PCR se realizó con $30 \mathrm{mg}$ de tejido muscular utilizando el kit AxyPrep Multisource Genomic DNA Miniprep
Kit (Axygen Biosciences, USA). La concentración y pureza de $\mathrm{ADN}$ se evaluó con un espectrofotómetro (A260/A280 nm) Nanodrop Lite (Thermo Scientific, USA) y el ADN fue almacenado a $-20{ }^{\circ} \mathrm{C}$ hasta su uso. Diseño de cebadores

Los cebadores se diseñaron con el software PrimerQuest Tool (IDT) con las secuencias obtenidas de GenBank ID GQ220043.1 (Cynoscion analis) (figura 1), ID AY850707.1 (Merluccius gayi gayi) y AY850709.1 (Merluccius gayi peruanus) (figura 2). Se utilizó regiones parciales del gen ATPase6 y regiones control, respectivamente. La especificidad teórica de los primers fue evaluada con el software BLASTn

Secuencias de primers diseñados utilizando el software PrimerQuest Tool (IDT).

C.analis 1

ATGACTGTAAGCCTCTTCGACCAATTTATATCCCCCACCTACTTAGGAGTCCCCCTGTTA

61

GCCCTGGCCCTCACCCTACCCTGAATTCTTTACCCCTCCCCCTCTGCCCGATGACTTAAT

121

AACCGCCTACTTACTCTCCAAGGCTGATTTATTAACCGATTTACCCAACAAATTCTTATA

181

CCCCTAAGTCTAGGCGGACATAAGTGGGCTCTAATCTTAACTTCCCTTATGATTTTCCTT

241

ATTACTCTAAACATTCTAGGCCTCCTTCCCTATACTTTTACCCCTACAACCCAGCTTTCC

301

CTCAACCTGGGCCTTGCAGTGCCACTCTGACTAGCTACAGTGCTTATCGGCCTACGCAAC

361

CAACCAACTGCTGCCCTCGGACATCTCCTACCAGAAGGTACCCCCACACCCCTAATCCCA

421

GTCCTTATTATCATCGAGACAATTAGCCTATTTATCCGCCCATTAGCCCTAGGCGTACGA

481

TTAACCGCCAACCTCACAGCCGGCCACCTCCTAATGCAACTCACTTCCTCAGCCGCCTTC

541

GTTATACTATCAATGATGCCCGCCGTGGCAGTCCTTACAACGATTCTCCTGTTCCTATTA

601

ACTCTCTTAGAAGTTGCCGTAGCTATAATTCAAGCCTACGTATTTGTCCTTCTTATAAGC

661

CTTTACCTACAAGAAAACGTCTAA

Figura 1. Secuencia conservada de Cynoscion analis (GQ220043.1). Diseño de primers secuencia verde (forward) y secuencia roja (reverse). 


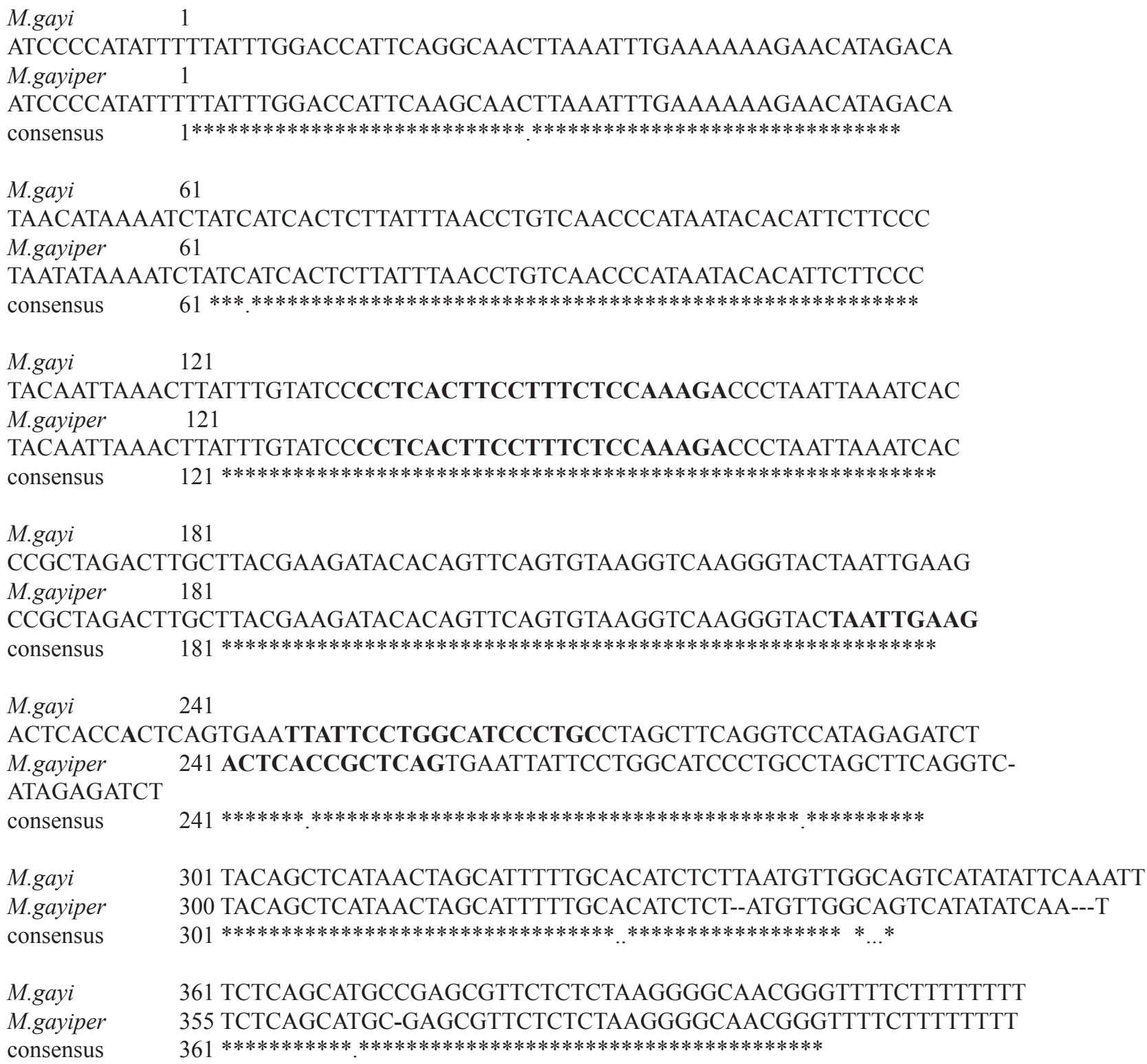

Figura 2. Alineamiento de secuencias consenso. Merluccius gayi gayi (AY850707.1), Merluccius gayi peruanus (AY850709.1). Diseño de primers secuencia verde (forward) y secuencia roja (reverse).

utilizando la base de datos GenBank, sólo se usaron aquellos cebadores que no presenten homología con especies cercanas.

\section{Elaboración de controles positivos y secuenciamiento}

Se trabajó un PCR en tiempo final con un volumen final de master mix de $12.5 \mu \mathrm{l}$ y $2.5 \mu \mathrm{l}$ de ADN, merluza: $2.5 \mathrm{mM} \mathrm{MgCl}, 200 \mathrm{mM}$ dNTPs, $0.5 \mu \mathrm{M}$ primers y $2 \mathrm{U}$ taq polimerasa (Thermo Fisher Scientific, USA), ayanque: $2 \mathrm{mM} \mathrm{MgCl}, 200 \mathrm{mM}$ dNTPs, 0.5 $\mathrm{uM}$ primers y $1.5 \mathrm{U}$ taq polimerasa (Thermo Fisher
Scientific, USA), 35 ciclos de $94{ }^{\circ} \mathrm{C}$ por $10 \mathrm{~min}, 95^{\circ} \mathrm{C}$ por $15 \mathrm{~s}, 60^{\circ} \mathrm{C}$ por $45 \mathrm{~s}, 70^{\circ} \mathrm{C}$ por $45 \mathrm{~s}$. El producto de PCR fue cuantificado utilizando un espectrofotómetro (A260/A280) Nanodrop Lite (Thermo Scientific, USA) e identificado por electroforesis en gel de agarosa $1.5 \%$. Las bandas de cada especie fueron purificadas con el kit AxyPrep DNA Gel Extraction (AXYGEN Biosciences, USA) y se enviaron a secuenciar a Macrogen (Corea del Sur). Se aceptaron las secuencias con una calidad Phred $>20$ y se evaluó la homología con las secuencias de referencia de GenBank utilizando el software BLASTn. 


\section{Condiciones de qPCR}

El qPCR fue estandarizado realizando curvas de $\mathrm{MgCl}_{2}$, cebadores y Taq polimerasa. El protocolo de ciclamiento se evaluó con diferentes temperaturas y tiempos de desnaturalización y alineamiento; trabajando gradientes de temperatura entre 56 y $65^{\circ} \mathrm{C}$. Se utilizó un volumen final de reacción de $12.5 \mu 1,1 \mathrm{X}$ LightCycler ${ }^{\circledR} 480$ High Resolution Melting Master (Roche, Suiza), $0.5 \mu \mathrm{M}$ cebadores, $94^{\circ} \mathrm{C}$ x $10 \mathrm{~min}, 40$ ciclos de $94^{\circ} \mathrm{C}$ x $45 \mathrm{~s}, 57^{\circ} \mathrm{C}$ x $45 \mathrm{~s}, 72^{\circ} \mathrm{C}$ x 1 min y una extensión final de $72^{\circ} \mathrm{C}$ x $10 \mathrm{~min}$. Seguido de una curva de disociación 65 a $95^{\circ} \mathrm{C} 1{ }^{\circ} \mathrm{C} / \mathrm{s}$. La amplificación se realizó en un termociclador LightCycler 96 (Roche, Suiza), y se analizó el ciclo umbral (Cq) y temperatura de melting $(\mathrm{Tm})$ con el software v.1.01.0.1320.

\section{Validación de qPCR}

Se sometió el ADN a degradación simulando las condiciones del proceso de conservas o productos que son sometidos a altas temperaturas. Se sometió $500 \mathrm{~g}$ de tejido de muscular de cada especie a $100{ }^{\circ} \mathrm{C}$ durante 30 minutos, se adicionó aceite vegetal y se llevó a esterilización mediante autoclave a $121{ }^{\circ} \mathrm{C}$ durante 30 minutos. La extracción de ADN degradado se trabajó con el kit DNeasy mericon Food Kit (Qiagen, Alemania) utilizando el protocolo de fragmentos pequeños y $200 \mathrm{mg}$ de muestra inicial por triplicado.

Eficiencia de amplificación qPCR y LDT

Se construyeron curvas estándar de diluciones decimales seriadas 1:10 por triplicado utilizando el ADN cuantificado y secuenciado para cada especie. Los parámetros aceptados para la curva estándar fueron; una pendiente ideal de -3.32 con un coeficiente de correlación (R2) mayor o igual a 0.98 . La eficiencia de amplificación fue calculada por la siguiente ecuación: $\mathrm{E}=[10$ (-1 / slope) -1] x 100\% (Bustin et al., 2009). El límite de detección (LDT) se considera como la menor concentración del target que se puede detectar de forma reproducible en un intervalo de confianza del 95\%. Se trabajaron 10 repeticiones de la menor concentración detectada por cada especie y se evaluó la $\mathrm{T} m$ y $\mathrm{Cq}$ de cada especie.

\section{Especificidad y sensibilidad de $q P C R$}

La sensibilidad relativa del PCR es la proporción de muestras positivas detectadas como positivas por el PCR cuando la muestra es positiva y la especificidad relativa es la proporción de muestras negativas que el PCR detecta como negativa cuando la muestra es negativa. Se describe estadísticamente como la probabilidad condicional de detectar positiva o negativa cuando la muestra es positiva o negativa (Dohoo, Martin, y Stryhn, 2003; Mäde, Petersen, Trümper, Stark, y Grohmann, 2004). Se validó la especificidad de lo cebadores para descartar una posible reacción cruzada, ensayando 10 repeticiones por cada set de cebadores y utilizando como muestra blanco diferentes especies comúnmente utilizadas en productos hidrobiológicos: bonito (Sarda sarda chilensis), anchoveta (Engraulis ringens), jurel (Trachurus picturatus), caballa (Scomber japonicus), atún (Thunnus spp.), machete (Ethmidium maculatum) y sardina (Sardinops sagax sagax).

Muestreo de productos enlatados, congelados y análisis $q P C R$

Se tomaron 10 muestras de filetes congelados de merluza de procedencia peruana, 10 muestras de nuggets de perico y 30 muestras de filete en conserva (10 latas de atún, 10 latas de bonito y 10 latas de caballa). Las muestras obtenidas indican especie, planta de procesamiento y país de procedencia, por lo tanto, los resultados pudieron ser validados con la información proporcionada en la etiqueta. Las muestras fueron tomadas en abril del 2018 en los principales centros comerciales de Lima.

Tabla 1. Primers y tamaño de amplicon bp

Especie

Cynoscion analis

Merluccius gayi gayi

Merluccius gayi peruanus
Secuencia 5'-3'

bp

Fwd: CCTCTGCCCGATGACTTAAT

Rev: CTAAGTCTAGGCGGACATAAGTG

106

Fwd: CCTCACTTCCTTTCTCCAAAGA

Rev: TTATTCCTGGCATCCCTGC

Fwd: CCTCACTTCCTTTCTCCAAAGA

Rev: TAATTGAAGACTCACCGCTCAG 


\section{Análisis estadístico}

El límite de detección (LDT), valores promedio de $\mathrm{Tm}$ y $\mathrm{Cq}$ se hallaron de manera reproducible: 10 repeticiones por especie para calcular la media aritmética $+\mathrm{S}$ utilizando el paquete estadístico Minitab 16.2.4.4 y el software v.1.01.0.1320 LightCycler 96 (Roche, Suiza).

La sensibilidad y especificidad fueron medidas con el nivel de correlación entre la data obtenida mediante identificación morfológica y qPCR a partir de los valores cualitativos definidos como positivo (1) o negativo (0). Los resultados fueron organizados en una tabla de contingencia de $2 \times 2$. Se obtuvieron los valores de concordancia mediante análisis de Kappa, así como los valores de sensibilidad, especificidad, valor predictivo positivo (VPP) y valor predictivo negativo (VPN) para el método validado qPCR. Los resultados fueron analizados con un nivel de significancia de 0.05 .

\section{RESULTADOS}

Procesamiento de muestra y extracción de ADN

El promedio de $\mathrm{ADN}$ recuperado fue de $17.70 \pm$

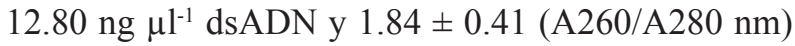

de pureza para las especies frescas y/o congelados trabajadas con el kit AxyPrep Multisource Genomic DNA Miniprep Kit (AXYGEN Biosciences, USA), el ADN extraído fue de buena calidad y permitió trabajar la estandarización del qPCR. Sin embargo, se obtuvieron falsos negativos, baja sensibilidad y recuperación de $\mathrm{ADN}$ altamente degradado.

\section{Diseño de cebadores}

Los cebadores diseñados no formaron productos inespecíficos ni dímeros (figura 3) ni presentaron homología con las secuencias de referencia en GenBank, los amplicones fueron de 106 bp Cynoscion analis, 133 bp Merluccius gayi gayi y 110 bp Merluccius gayi peruanus, las secuencias se detallan en la tabla 1. Los cebadores no amplificaron para otras especies pelágicas utilizadas en productos hidrobiológicos (tabla 2).

\section{Elaboración de controles positivos y secuenciamiento}

Las secuencias obtenidas fueron alineadas con las secuencias de referencia utilizando el software BLASTn, no se presentó homología con ningún organismo acuático de la base de datos NCBI (National Center for Biotechnology Information), se demostró la especificidad de los cebadores y del producto obtenido.

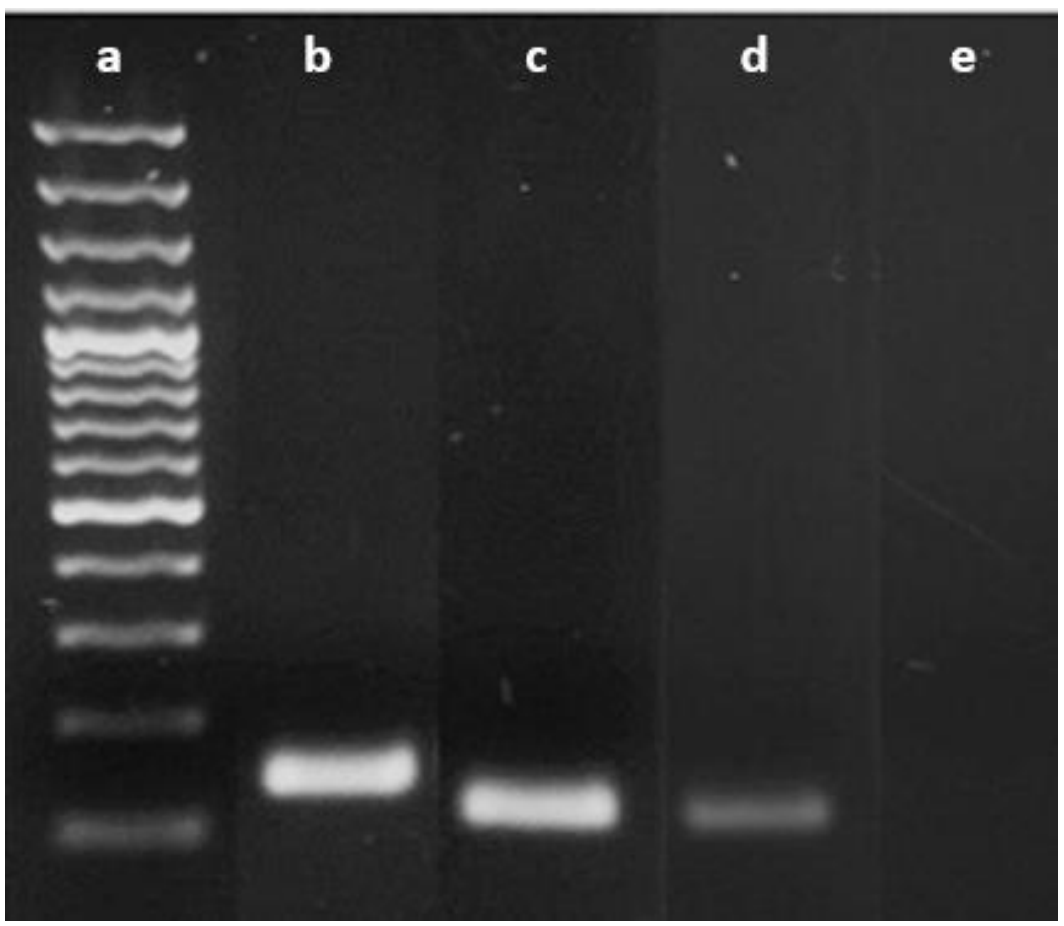

Figura 3. Electroforesis en gel de agarosa 2\%. (a) ladder 100bp. (b) Merluccius gayi gayi 133 bp. (c) Merluccius gayi peruanus 110 bp. (d) Cynoscion analis 106 bp. (e) control negativo. 
Tabla 2. Especificidad qPCR. Amplificación cruzada del ensayo con ADN sometido a altas temperaturas y aceite, 10 repeticiones por especie. +: Positivo, -: negativo.

\section{Detección qPCR}

Primers

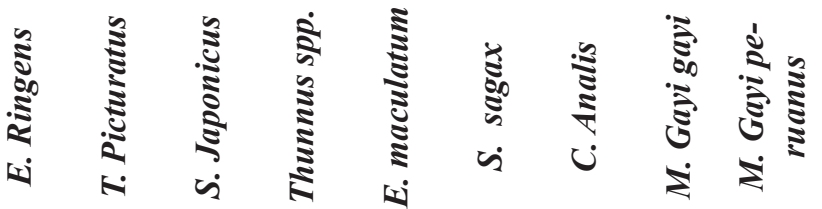

\section{Cynoscion analis}

\section{Merluccius gayi gayi}

Merluccius gayi peruanus
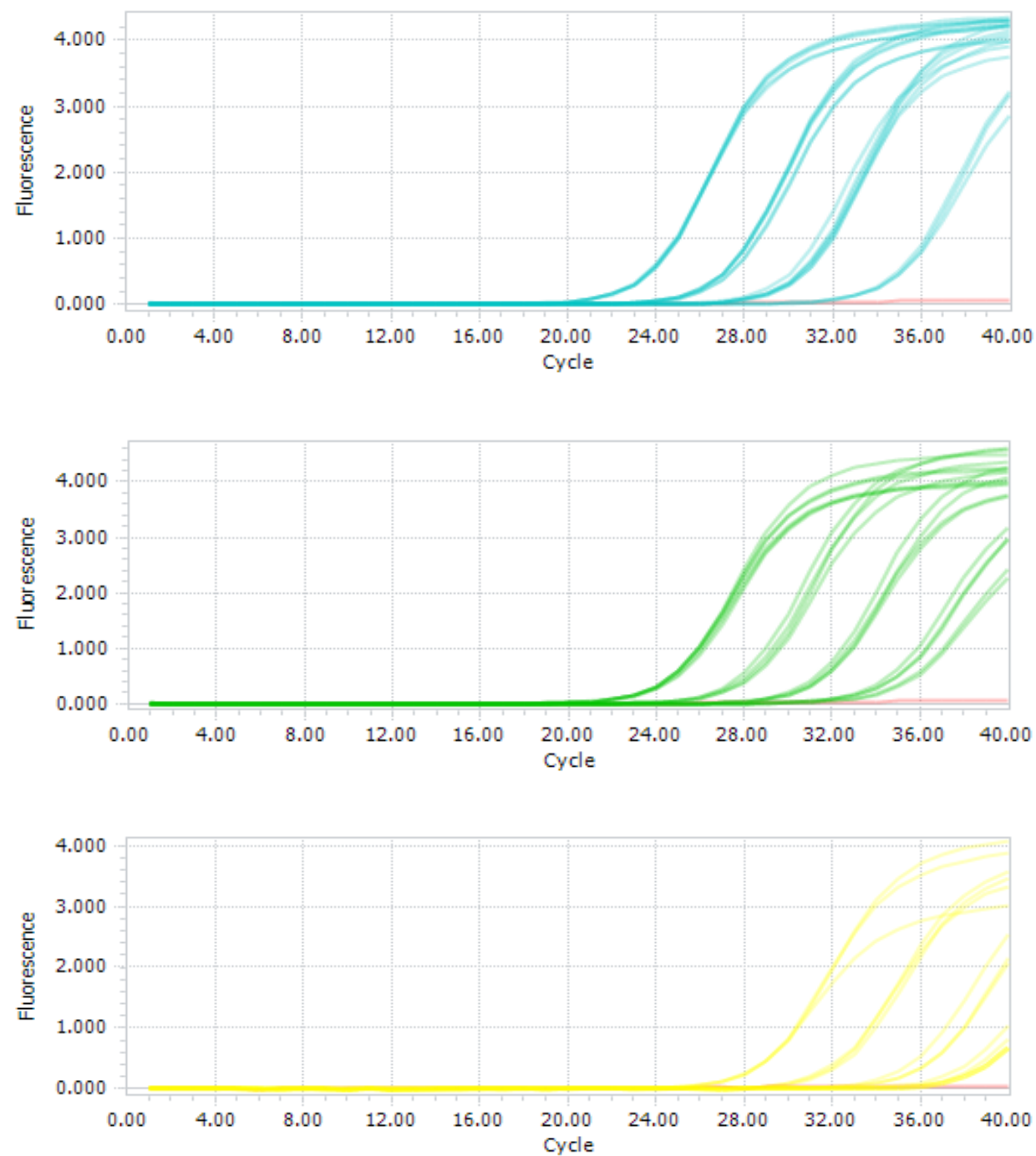

Figura 4. Curvas estándar. Merluccius gayi gayi (a), Merluccius gayi peruanus (b) y Cynoscion analis $(\mathrm{c})$. 


\section{Condiciones de qPCR}

La amplificación de las 3 especies se representa con una curva sigmoidea por arriba del threshold y menor a 37.54 \pm 0.29 Cq Cynoscion analis, $32.78 \pm 0.63$ Cq Merluccius gayi gayi y $33.54 \pm 0.51 \mathrm{Cq}$ (figura 4). La temperatura de melting para cada producto fue de $79.50 \pm 0.33$ de Cynoscion analis, $80.13 \pm 0.13$ de Merluccius gayi y $78.84 \pm 0.58$ Merluccius gayi peruanus (figura 5).

\section{Validación de qPCR}

El método de extracción con el kit DNeasy mericon Food Kit (Qiagen,Alemania) permitió una recuperación media de $6.45 \pm 3.08 \mathrm{ng} / \mu \mathrm{l}$ y una pureza A260/A280 de $2.01 \pm 0.12 \mathrm{ng} / \mu \mathrm{l}$ para muestra sometidas a altas temperaturas. El ADN extraído con el método de extracción para ADN altamente fragmentado permitió trabajar la validación del qPCR.

Eficiencia de amplificación qPCR y LDT

El slope de las curvas estándar se encuentran entre -3.2507 y -3.397 , con coeficiente de regresión (R2) mayor a 0.99 en las 3 especies (Figura 6) y eficiencias de amplificación de $97.13 \%$ en Merluccius gayi gayi, $98.33 \%$ en Merluccius gayi peruanus y $102.93 \%$ en Cynoscion analis. El límite de detección fue de $0.00122 \mathrm{ng} \mu \mathrm{l}-1$ de ADN Merluccius gayi gayi, $0.00116 \mathrm{ng} \mu \mathrm{l}-1$ de ADN Merluccius gayi peruanus y $0.00163 \mathrm{ng} \mu \mathrm{l}-1$ de ADN Cynoscion analis (Figura 3).
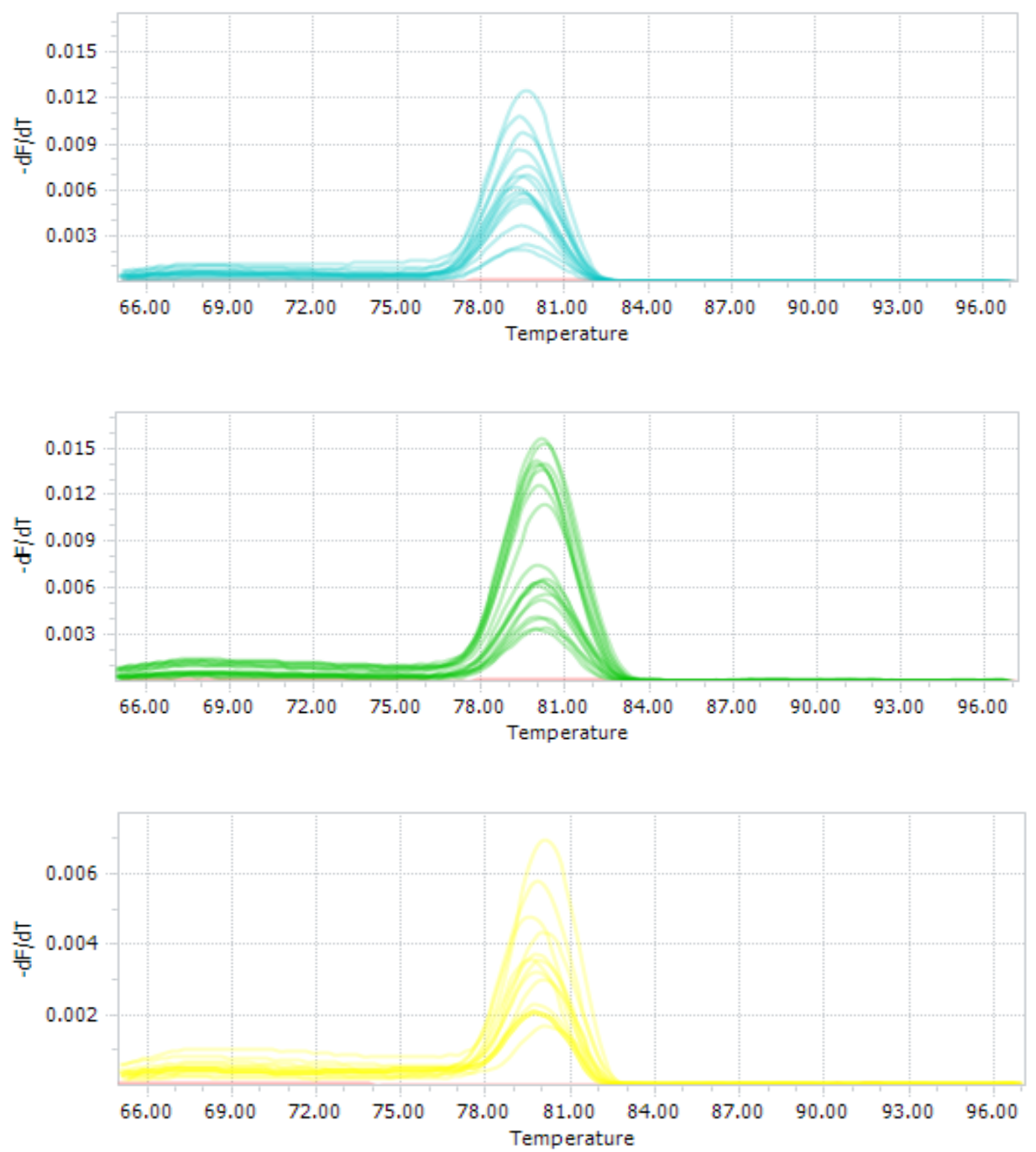

Figura 5. Picos de melting. Merluccius gayi gayi (a), Merluccius gayi peruanus (b) y Cynoscion analis $(\mathrm{c})$ 


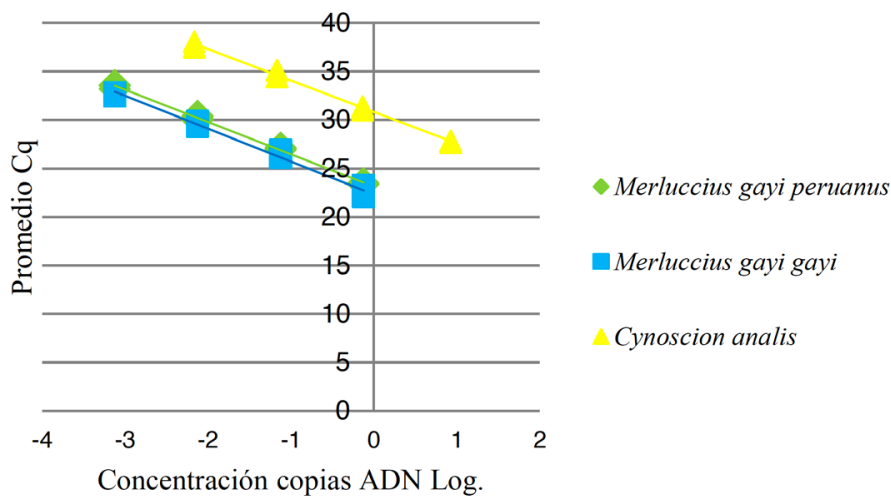

Figura 6. Regresión lineal de las especies acuáticas detectadas en qPCR tiempo real. Los valores promedio de $\mathrm{Cq}$ inversamente proporcional a la concentración logarítmica de las copias de ADN.

Especificidad y sensibilidad de qPCR

Se encontró un nivel de concordancia del 100\% y un valor predictivo positivo y negativo del $100 \%$, sólo las muestras que contenían el blanco amplificaron y ninguna de las especies ensayadas presentó reacción cruzada con anchoveta, bonito, jurel, caballa, atún, machete y sardina (Cuadro 2).

Muestreo de productos enlatados y congelados, análisis por $q P C R$

Las latas de atún provenientes de Asia fueron negativas a merluza (Merluccius gayi gayi) y ayanque. El 35\% de muestras positivas a merluza provienen de Sudamérica. Las latas comercializadas como caballa fueron positivas a merluza en un $8 \%$. El $100 \%$ de las conservas de bonito fueron positivas a merluza y el $2 \%$ positivas a ayanque y merluza.

El $100 \%$ de los filetes congelados de merluza corresponden a la especie Merluccius gayi peruanus, especie descrita en la etiqueta, y el $80 \%$ de los nuggets que indicaban perico Coryphaena hippurus en la etiqueta, fueron positivos a merluza.

\section{DISCUSIÓN}

Los consumidores de todos los mercados a nivel mundial esperan cada vez más que la industria pesquera diseñe y aplique medidas para la seguridad y trazabilidad de los productos alimenticios hidrobiológicos y así asegurar que sean de alta calidad, auténticos y debidamente etiquetados con la información necesaria. Por lo tanto, se requiere de técnicas rápidas y fiables para controlar la seguridad de los productos y prevenir el fraude.

Uno de los métodos usados para la identificación de especies marinas es la detección de proteínas, 2-D electroforesis y MALDI-TOF MS (Carrera, Cañas, Piñeiro, Vázquez, y Gallardo, 2006). Sin embargo, al ser empleadas en productos procesados a altas temperaturas presentan baja especificidad debido a la destrucción estructural de las proteínas lo que dificulta su identificación. Por ello el uso del PCR es adecuado para la caracterización de especies en productos que sufren alteraciones amplificando ADN altamente degradado.

En el estudio realizado por Quintero et al., 2001, detectaron diferentes especies de merluza en muestras de tejido muscular fresco y productos procesados con diferentes concentraciones deADN usando PCR-RFLP, amplificaron un fragmento consenso que contiene la variación nucleotídica entre especies y son digeridos con una enzima de restricción formando fragmentos de restricción de diferentes tamaños que permiten identificar los alelos por medio de electroforesis. Sin embargo, la desventaja que presenta este análisis es la difícil identificación simultánea de varios SNP (polimorfismo de un solo nucleótido) debido a que las enzimas de restricción deben ser específicas para cada uno lo cual toma mucho tiempo (Rasmussen, H. B., 2012).

SYBR Green I es un fluorocromo que se une al ADN de doble cadena (dsADN) emitiendo una fluorescencia, pero puede detectar dímeros y productos 
inespecíficos, produciendo falsos positivos (Loftis \& Reeves, 2012). Sin embargo, el análisis de las curvas de fusión ayuda a determinar la $\mathrm{Tm}$ de cada producto.

La diferencia morfológica entre las dos subespecies de merluza, Merluccius gayi gayi y Merluccius gayi peruanus es poco significativa (Hernandez, Galleguillos, y Oyarzun, 2000) siendo mayor al ser expuestas a procesos de cambios en su estructura. En este estudio se detectó en tiempo real ambas especies obteniendo $\mathrm{Tm}$ diferentes lo que permite caracterizar las especies sin necesidad de utilizar enzimas de restricción y electroforesis de resolución post PCR.

El método de Perez y Garcia-Vazquez (2004) utilizó el PCR en tiempo final de un solo paso, detectando el gen 5S rRNA para la identificación de 9 especies de merluza en productos procesados. Sin embargo, los cebadores utilizados, a pesar de tener un producto de PCR corto (120 bp), no detectaron la sub-especie de merluza muestreada en el país. Por lo tanto se diseñaron cebadores específicos de secuencias parciales de regiones control de "merluza peruana" Merluccius gayi peruanus y el género merluza. Se recomienda realizar trabajos filogénicos de la familia Merlucciidae distribuidos en el país, océano Pacífico y océano Atlántico.

Vergara-Chen, Aguirre, González-Wangüemert, y Bermingham (2009) realizaron un estudio de filogenia que tomaba como base el ADN mitocondrial ATPase $8 / 6$ y Cyt b de especies del grupo Cynoscion. Los cebadores utilizados en la validación pertenecen a una secuencia parcial de 106 bp del gen ATPase 6 que fue validada por secuenciamiento y se detectó en la muestras de ayanque tomadas en diferentes terminales pesqueros del país, lo que demuestra la homología de la secuencia estudiada con las muestras del golfo de Guayaquil en el océano pacífico, pudiendo detectar la especie en diversos productos hidrobiológicos de diferente procedencia.

La producción de conservas y harina de pescado son procesos que implan alta transformación debido a las altas temperaturas a las que son sometidos los insumos. En un estudio de PCR realizado por Fumière et al. (2006) para la detección de especies prohibidas en harinas de pescado, no se detectaron productos de PCR mayores a $174 \mathrm{bp}$. Esto podría deberse a la baja tasa de purificación de $\mathrm{ADN}$ con métodos de extracción que no sean capaces de recuperar fragmentos pequeños y/o la presencia de inhibidores en las muestras. En este estudio no se tuvieron problemas de recuperación, se validó un PCR en tiempo real para la identificación de productos de tamaños pequeños: 106 bp Cynoscion analis, 133 bp Merluccius gayi gayi y 110 bp Merluccius gayi peruanus. Por lo tanto, es importante el uso de protocolos capaces de recuperar fragmentos cortos de ADN que minimice la cantidad de inhibidores y pueda ser amplificado eficientemente.

Se ensayó el método validado con muestras de conservas y congelados comercializados en el Perú. Los productos procedentes de Sudamérica fueron positivos a merluza y ayanque. Sin embargo, se recomienda ampliar el alcance de la técnica y el muestreo para identificar la presencia de múltiples especies y evaluar la situación actual del país en la industria de hidrobiológicos. En Estados Unidos reportaron entre 30 a $58 \%$ de muestras mal etiquetadas (Warner, Timme, Lowell, y Hirschfield, 2013), el 25\% de los productos de bacalao en Reino Unido e Irlanda corresponden a especies de un valor comercial menor a la descrita en la etiqueta (Corrado et al. 2016). Al igual que en España el 32.5\% de las muestras correspondían a especies de menor valor comercial al bonito del norte o atún blanco (Thunnus alalunga), sustituidas por el bonito listado (Katsuwonus pelamis), el patudo (Thunnus obesus) o el bonito (Sarda sarda), todas las muestras incorrectamente etiquetadas correspondían a muestras congeladas (Asensio, González, Pavón, García, y Martín, 2008). En Italia, el $82 \%$ de las muestras de mero (Epinephelus spp.), perca (Perca spp.) y pez espada (Xiphias gladius) fueron etiquetadas incorrectamente, y cerca del $50 \%$ eran sustituidas por tipos de peces que podían ser dañinos para la salud (Warner et al. 2013).

La validación del ensayo demuestra que es 100\% específico y sensible para la detección de ADN sometido a altas temperaturas y con presencia de inhibidores, siendo un método adecuado para la identificación de las especies trabajadas en productos hidrobiológicos como conservas o harina de pescado, que debido al proceso de transformación son de difícil identificación y dificulta la validación del correcto etiquetado. Se logró la identificación de Merluccius gayi gayi, Merluccius gayi peruanus y Cynoscion analis mediante qPCR con eficiencias de amplificación mayores a 97\% y límites de detección por debajo de 0.00163 ng $\mu \mathrm{l}^{-1}$ DNA. Las muestras de conservas corridas con el ensayo validado demostraron que existe la presencia de especies no descritas en la etiqueta. En el Perú no se han realizado estudios similares, por tal motivo se requiere un método de detección rápido, fiable y con mayor alcance que pueda ser implementado por las 
autoridades competentes para controlar el fraude en la industria hidrobiológica y certificar los productos comercializados.

El presente trabajo fue financiado por el Programa Nacional de Innovación para la Competitividad y Productividad (Innóvate Perú), de acuerdo al contrato 113-PNICP-PIAP-2015.

\section{Declaraciones de conflicto de interés: Ninguna}

\section{Correspondencia:}

Marcela Mora Chiò

Correo electrónico: marcela.mora.c@upch.pe

\section{REFERENCIAS BIBLIOGRÁFICAS}

1. Aas, K., \& Elsayed, S. M. (1969). Characterization of a major allergen (cod): Effect of enzymic hydrolysis on the allergenic activity. Journal of Allergy, 44(6), 333-343.

2. Akasaki, T., Yanagimoto, T., Yamakami, K., Tomonaga, H., \& Sato, S. (2006). Species Identification and PCR-RFLP Analysis of Cytochrome b Gene in Cod Fish (Order Gadiformes) Products. Journal of Food Science, 71(3), C190C195.

3. Asensio, L., González, I., Pavón, M. A., García, T., \& Martín, R. (2008). An indirect ELISA and a PCR technique for the detection of grouper (Epinephelus marginatus) mislabeling. Food Additives and Contaminants, 25(6), 677-683.

4. Bachur, S. (2014). Revisión de los principales métodos de detección e identificación de proteínas animales procesadas en alimentos balanceados. SNS, 5(6), 15-27.

5. Bernhisel-Broadbent, J., Strause, D., \& Sampson, H. A. (1992). Fish hypersensitivity. II: Clinical relevance of altered fish allergenicity caused by various preparation methods. Journal of Allergy and Clinical Immunology, 90(4), 622-629.

6. Bustin, S. A., Benes, V., Garson, J. A., Hellemans, J., Huggett, J., Kubista, M., ...Wittwer, C. T. (2009). The MIQE guidelines: Minimum information for publication of quantitative real-time PCR experiments. Clinical Chemistry, 55(4), 611-622.

7. Carrera, M., Cañas, B., Piñeiro, C., Vázquez, J., \& Gallardo, J. M. (2006). Identification of commercial hake and grenadier species by proteomic analysis of the parvalbumin fraction. Proteomics, 6(19), 52785287.

8. Corrado, F., Cutarelli, A., Criscuolo, D., De Roma, A., Cecere, B., Simonetti, D., \& Varricchio, E. (2016). Identification of fraud in trade in processed fish products by DNA analysis. IMEKOFOODS, 2, 1-4.

9. De Martino, M., Novembre, E., Galli, L., de Marco, A., Botarelli, P., Marano, E., \& Vierucci, A. (1990).

10. Allergy to different fish species in cod-allergic children: in vivo and in vitro studies. Journal of Allergy and Clinical Immunology, 86(6), 909-914.

11. Ministerio de la Producción.(4 de agosto del 2007). Decreto Supremo $N^{\circ}$ 015-2007-PRODUCEModificación del Reglamento de la Ley General de Pesca, aprobado por el Decreto Supremo $N^{\circ} 012$ 2001-PE. Lima, Perú: Diario Oficial El Peruano.

12. Dohoo, I., Martin, W., \& Stryhn, H., (2003). Screening Diagnostic Tests. (pp. 86-113). Charlottetown, Canada: Veterinary Epidemiologic Research AVC Inc.

13. Dooley, J. J., Sage, H. D., Clarke, M. A. L., Brown, H. M., \& Garrett, S. D. (2005). Fish species identification using PCR- RFLP analysis and labon-a-chip capillary electrophoresis: application to detect white fish species in food products and an interlaboratory study. Journal of agricultural and food chemistry, 53(9), 3348-3357.

14. Organización de las Naciones Unidas para la Alimentación y la Agricultura. (2016). El consumo mundial de pescado per cápita supera por primera vez los 20 kilogramos anuales. Washington DC: Organización de las Naciones Unidas para la Alimentación y la Agricultura. Recuperado de: http:// www.fao.org/news/story/es/item/423048/icode/

15. Fumière, O., Dubois, M., Baeten, V., von Holst, C., \& Berben, G. (2006). Effective PCR detection of animal species in highly processed animal byproducts and compound feeds. Analytical and Bioanalytical Chemistry, 385(6), 1045-1054.

16. Hargin, K. D. (1996). Authenticity issues in meat and meat products. Meat Science, 43, 277-289.

17. Hernandez, C., Galleguillos, R., \& Oyarzun, C. (2000). Diferenciación genética de Merluccius gayi gayi y Merluccius gayi peruanus (Pisces, Merlucciidae) y antecedentes paleogeográficos de su área de distribución. Revista chilena de historia natural, 73(1), 23-29.

18. Kuehn, A., Scheuermann, T., Hilger, C., \& Hentges, F. (2010). Important variations in parvalbumin content in common fish species: a factor possibly contributing to variable allergenicity. International archives of allergy and immunology, 153(4), 359-366.

19. Loftis, A., \& Reeves, W. (2012). Principles of RealTime PCR. En: C. Wang, B. Kaltenboeck, \& M. Freeman. Veterinary PCR Diagnosis. Danvers MA, USA: Bentham Science eBooks.

20. Mäde, D., Petersen, R., Trümper, K., Stark, R., \& Grohmann, L. (2004). In-house validation of a realtime PCR method for rapid detection of Salmonella ssp. in food products. European Food Research and Technology, 219(2), 171-177. 
21. Nagase, M., Maeta, K., Aimi, T., Suginaka, K., \& Morinaga, T. (2009). Authentication of flying-fishmeal content of processed food using PCR-RFLP. Fisheries Science, 75(3), 811-816.

22. Perez, J., \& Garcia-Vazquez, E. (2004). Genetic identification of nine hake species for detection of commercial fraud. Journal of food protection, 67(12), 2792-2796.

23. Quinteiro, J., Vidal, R., Izquierdo, M., Sotelo, C. G., Chapela, M. J., Pérez-Martín, R. I. \& Rosa, C. (2001).

24. Identification of hake species (Merluccius genus) using sequencing and PCR- RFLP analysis of mitochondrial DNA control region sequences. Journal of Agricultural and Food Chemistry, 49(11), 51085114.
25. Rasmussen, H. B. (2012). Restriction fragment length polymorphism analysis of PCR-amplified fragments (PCR-RFLP) and gel electrophoresis-valuable tool for genotyping and genetic fingerprinting. In S. Magdeldin (ed.). GEL ELECTROPHORESIS - PRINCIPLES AND BASICS.( pp. 315-334).Rijeka, Kroatien: InTech.

26. Vergara-Chen, C., Aguirre, W. E., GonzálezWangüemert, M., \& Bermingham, E. (2009). A mitochondrial DNA based phylogeny of weakfish species of the Cynoscion group (Pisces: Sciaenidae). Molecular phylogenetics and evolution, 53(2), 602-607.

27. Wolf, C., Burgener, M., Hübner, P., \& Lüthy, J. (2000). PCR-RFLP analysis of mitochondrial DNA: differentiation of fish species. LWT-Food Science and Technology, 33(2), 144-150.

28. Warner, K., Timme, W., Lowell, B., \& Hirschfield, M. (2013). Oceana study reveals seafood fraud nationwide (p. 2014). Washington, DC: Oceana. 